\title{
Familiality of neural preparation and response control in childhood attention deficit-hyperactivity disorder
}

\author{
B. Albrecht ${ }^{1,2 *} \uparrow$, D. Brandeis ${ }^{2,3,4,5} \dagger$, H. Uebel ${ }^{1}$, L. Valko ${ }^{3}$, H. Heinrich ${ }^{6,7}$, R. Drechsler ${ }^{3}$, A. Heise ${ }^{1}$ \\ U. C. Müller ${ }^{3,8}$, H.-C. Steinhausen ${ }^{3,9,10}$, A. Rothenberger ${ }^{1}$ and T. Banaschewski ${ }^{2}$ \\ ${ }^{1}$ Child and Adolescent Psychiatry, University of Göttingen, Göttingen, Germany \\ ${ }^{2}$ Department of Child and Adolescent Psychiatry and Psychotherapy, Central Institute of Mental Health, Medical Faculty Mannheim/ \\ Heidelberg University, Mannheim, Germany \\ ${ }^{3}$ Department of Child and Adolescent Psychiatry, University of Zurich, Zurich, Switzerland \\ ${ }^{4}$ Center for Integrative Human Physiology, University of Zurich, Zurich, Switzerland \\ ${ }^{5}$ Neuroscience Center Zurich, University of Zurich and ETH Zurich, Zurich, Switzerland \\ ${ }^{6}$ Department of Child and Adolescent Mental Health, University of Erlangen, Erlangen, Germany \\ ${ }^{7}$ Heckscher-Klinik, Munich, Germany \\ ${ }^{8}$ Interkantonale Hochschule für Heilpädagogik Zürich, Switzerland \\ ${ }^{9}$ Aalborg Psychiatric Hospital, Aarhus University Hospital, Aalborg, Denmark \\ ${ }^{10}$ Department of Clinical Psychology and Epidemiology, University of Basel, Basel, Switzerland
}

Background. Patients with attention deficit-hyperactivity disorder (ADHD) exhibit difficulties in multiple attentional functions. Although high heritability rates suggest a strong genetic impact, aetiological pathways from genes and environmental factors to the ADHD phenotype are not well understood. Tracking the time course of deviant task processing using event-related electrophysiological brain activity should characterize the impact of familiality on the sequence of cognitive functions from preparation to response control in ADHD.

Method. Preparation and response control were assessed using behavioural and electrophysiological parameters of two versions of a cued continuous performance test with varying attentional load in boys with ADHD combined type $(n=97)$, their non-affected siblings $(n=27)$ and control children without a family history of ADHD $(n=43)$.

Results. Children with ADHD and non-affected siblings showed more variable performance and made more omission errors than controls. The preparatory Cue-P3 and contingent negative variation $(\mathrm{CNV})$ following cues were reduced in both ADHD children and their non-affected siblings compared with controls. The NoGo-P3 was diminished in ADHD compared with controls whilst non-affected siblings were located intermediate but did not differ from both other groups. No clear familiality effects were found for the Go-P3. Better task performance was further associated with higher CNV and P3 amplitudes.

Conclusions. Impairments in performance and electrophysiological parameters reflecting preparatory processes and to some extend also for inhibitory response control, especially under high attentional load, appeared to be familially driven in ADHD and may thus constitute functionally relevant endophenotypes for the disorder.

Received 13 December 2011; Revised 12 October 2012; Accepted 12 October 2012; First published online 3 December 2012

Key words: Attention deficit-hyperactivity disorder, contingent negative variation, Continuous Performance Test, endophenotypes, event-related potentials, NoGo-P3.

\section{Introduction}

Attention deficit-hyperactivity disorder (ADHD) goes hand in hand with multiple dysfunctions in neuronal networks responsible for attention and response control (Pennington \& Ozonoff, 1996; Castellanos \&

* Address for correspondence: Dr B. Albrecht, Child and Adolescent Psychiatry, University of Göttingen, von Siebold-Straße 5, 37075 Göttingen, Germany.

(Email: balbrec@gwdg.de)

$\dagger$ These authors contributed equally to this work.
Tannock, 2002). Heritability estimates exceeding 70\% indicate a strong genetic impact on the expression of the disorder, despite weak associations between ADHD and each individual risk allele, and a limited understanding of developmental pathways from genetic and environmental factors (Castellanos \& Tannock, 2002; Banaschewski et al. 2005; Faraone et al. 2005). Endophenotypes, which are quantitative and heritable vulnerability traits characterized by more fundamental biological properties in between, on the one hand, genetic and environmental risk factors and 
on the other hand, the phenotype, may help to clarify these associations. It is expected that endophenotypes show larger and more specific genetic effects than diagnostic phenotypes (Doyle et al. 2005) and may serve as useful intermediate constructs that explain the heterogeneity of the ADHD phenotype (Buitelaar, 2005; Banaschewski et al. 2007; Rommelse et al. 2007a). This particularly holds for endophenotypes based on neural activity (Meyer-Lindenberg \& Weinberger, 2006).

In a recent study, we showed that action monitoring as reflected by several performance and electrophysiological parameters was impaired in boys with ADHD and intermediate in their non-affected siblings compared with controls without a family history of ADHD (Albrecht et al. 2008, 2009). Thus, deficits in these parameters may be a consequence of specific genes or environmental factors that are shared in the families. Similar familial deficits were also reported for performance in a Stroop task and an oral arithmetic test (Doyle et al. 2005), with several parameters of motor inhibition (Slaats-Willemse et al. 2003) and also for quantitative electroencephalography (EEG) parameters (Loo et al. 2010).

While action-monitoring tasks require frequent responses to tap cognitive control mechanisms continuously, the assessment of preparation and response control requires a different approach that separates these processes in time to capture their temporal progression. In this study, the cued Continuous Performance Test (CPT) combining vigilance and cued Go-NoGo tasks (Rosvold et al. 1956) was used to characterize these aspects of executive functions in ADHD (van Leeuwen et al. 1998; Banaschewski et al. 2003). The paradigm requires a simple response only if an infrequent cue stimulus is followed by a prespecified target. Thus, the rare cues require preparation for a Go-NoGo task: if followed by a target a response needs to be executed, but if followed by a non-target, the prepared response must be withheld through inhibitory response control. CPT performance in children with ADHD is typically impaired, consistent with diminished sustained attention and control (Losier et al. 1996; Huang-Pollock et al. 2006). Additionally, event-related potentials (ERPs) can directly clarify deviance and timing of the covert brain processes leading to overt performance (Banaschewski \& Brandeis, 2007).

Cues elicit a broad positive deflection maximal over parietal areas associated with attentional orienting and resource allocation, which is reduced in children and adults with ADHD (van Leeuwen et al. 1998; Banaschewski et al. 2003; McLoughlin et al. 2010). This Cue-P3 is followed by a centrally negative slow cortical potential field that terminates with the presentation of the next stimulus (contingent negative variation; $\mathrm{CNV}$ ) and reflects preparation, anticipation and time estimation, which is not present after irrelevant distractors or non-targets (Walter et al. 1964). Neurophysiological studies have implicated dopaminergic control of the CNV (Linssen et al. 2011; Kratz et al. 2012) and an ensemble of thalamo-cortical structures including the dorsal anterior cingulate cortex, frontal cortex, thalamus and midbrain dopaminergic nuclei involved in CNV generation (Gomez et al. 2003; Fan et al. 2007; Lutcke et al. 2008). Time processing and preparation problems in patients with ADHD are associated with reduced activation in brain regions implicated in CNV generation (Rubia et al. 1999; Smith et al. 2008) and are considered as a candidate endophenotype (Castellanos \& Tannock, 2002; Rommelse et al. 2007b; Plummer \& Humphrey, 2008; Himpel et al. 2009). In line with these considerations, CNV is consistently reduced in ADHD (Hennighausen et al. 2000 ; Perchet et al. 2001; Banaschewski et al. 2003, 2008) and may represent a persistent deficit in patients with ADHD (Valko et al. 2009; Doehnert et al. 2010).

In trials following such cues, response control is required, and the difference in task demand between Go and NoGo trials is paralleled in the ERP. Following enhanced N2 amplitude in NoGo trials indexing conflict monitoring (Banaschewski et al. 2004), also the subsequent P3 is modulated (Fallgatter \& Strik, 1999). Cued non-targets that require suppressing a prepared response evoke a NoGo-P3 maximal at fronto-central sites. Several authors suggest that it may reflect response inhibition (Pfefferbaum et al. 1985; Fallgatter et al. 1999; Fallgatter \& Strik, 1999) or termination of motor activation through cortical deactivation in motor areas (Kopp et al. 1996; Falkenstein et al. 1999; Verleger et al. 2006). Clearly, these aspects are interrelated, and thus the NoGo-P3 may be generated by several processes of terminal inhibitory response control in the medial or anterior cingulate cortex, premotor areas and frontal areas (Kiefer et al. 1998; Strik et al. 1998; Weisbrod et al. 2000; Fallgatter et al. 2002; Verleger et al. 2006; Beste et al. 2008). Clinical studies have shown that the NoGo-P3 is altered in amplitude or anteriorization in patients with ADHD, and represents a persistent neurophysiological deficit (Brandeis et al. 2002; Fallgatter et al. 2004, 2005; Valko et al. 2009; Dhar et al. 2010; Doehnert et al. 2010).

The more parietally distributed Go-P3 elicited after cued target stimuli has been associated with several attentional functions such as evaluation of stimuli, closure or resource allocation (Polich \& Kok, 1995; Kok, 2000), and may thus reflect aspects of executive response control. Explicit analyses of the Go-P3 in ADHD are rare, but some instances of diminished 
amplitude for patients have been seen (Strandburg et al. 1996; Overtoom et al. 1998; Banaschewski et al. 2004; Lawrence et al. 2005).

Taken together, the CPT elicits several separable phases of attentional and executive processing. Attentional orienting and resource allocation after cue onset are associated with the Cue-P3, and followed by preparation for and anticipation of the next trial as reflected by the CNV. The strength of the CNV has been associated with response speed. If the subsequent trial is a Go trial, execution of the prepared response is required, and this target stimulus-evoked Go-P3 reflects perceptual resource allocation to the Go stimulus as well as context updating. NoGo trials instead require the termination of the prepared motor response which is associated with a P3 that has a more anterior topography than the Go-P3 (Banaschewski et al. 2004). The aim of this study was to test whether performance and electrophysiological parameters in the time course from preparation to response execution or response control show familiality and may thus reflect potential endophenotypes for ADHD. It is further tested whether preparation and response control are particularly impaired in ADHD if additional need for cognitive control is induced by the presentation of additional incompatible flanker stimuli in the CPT. Moreover, correlational analyses were performed to explore the relationship between performance parameters and brain activity measures, and electrical neuroimaging techniques were used to locate the electrical neuronal sources of the ERPs for clarifying the neuronal networks responsible.

\section{Method}

Subjects

Recruitment of subjects was carried out as part of the International Multi-Center ADHD Genetics Project (IMAGE). Ethical approval for this study was obtained from the local ethical review boards. Details concerning recruitment and the diagnostic procedure can be found elsewhere (Andreou et al. 2007; Albrecht et al. 2008). Briefly, recruitment of ADHD sibling pairs was conducted as part of the IMAGE study (Asherson et al. 2007) from specialist clinics for ADHD or child and adolescent psychiatrists in private practice in Zurich, Switzerland and Göttingen, Germany. Controls were recruited from local schools or sports clubs. Following screening by behavioural rating questionnaires obtained from both parents and teacher [long versions of Conners' rating scales (Conners et al. 1998a, b) and the Strengths and Difficulties Questionnaire (SDQ; Goodman, 1997, Woerner et al. 2004)], a semistructured clinical interview (Parental Account of
Children's Symptoms; Taylor et al. 1986, 1987) was applied by trained investigators in order to verify ADHD diagnosis.

A total of 289 European Caucasian children and adolescents aged 8 to 16 years with an estimated Hamburg-Wechsler Intellegence Test for Children Kinder (HAWIK-IQ) above 80 (Sattler, 1992) and no known child psychiatric disorder that may mimic ADHD were initially included. They belong to one of three subgroups: (1) children and adolescents with a DSM-IV diagnosis of ADHD combined type; (2) nonaffected siblings of those with a DSM-IV diagnosis of ADHD, without a clinical diagnosis of ADHD; and (3) unrelated healthy controls without a clinical diagnosis or a known family history of ADHD.

Since gender ratio differed across groups $\left(\chi_{(2)}^{2}=40.8\right.$, $p<0.01)$ and girls with ADHD were outnumbered and furthermore considerably younger, only the subsample of boys $(n=193)$ was analysed here. Due to artefacts in the EEG, datasets from three controls, three non-affected siblings and 20 participants with ADHD needed to be excluded, but exclusion ratio did not differ significantly across groups $\left(\chi_{(2)}^{2}=3.5, p=0.17\right)$. Thus, groups of 97 boys with ADHD, 27 male nonaffected siblings of ADHD patients and 43 controls were finally included. The groups were matched for age $\left(F_{2,164}=0.3, p=0.77, \eta_{\mathrm{p}}^{2}<0.01\right)$, but showed a tendency towards differences in intelligence quotient (IQ) $\left(F_{2,164}=2.8, p=0.07, \eta_{\mathrm{p}}^{2}<0.03\right.$; children with ADHD had lower IQ than controls). Non-affected sibling exhibited only subtle, subclinical increases in hyperactivity scores and parent ratings (for further description of the sample, see Table S1 of the Supplementary material).

\section{Stimuli and task}

Assessments were carried out on 2 days in videocontrolled, noise-shielded and slightly dimmed rooms at both departments, with the order of neurophysiological and neuropsychological testing following a randomization scheme. To assess preparation and response control and the impact of attentional load thereon, the Standard-CPT as well as a CPT Flanker version (Flanker-CPT) incorporating additional incompatible stimuli were used (Doehnert et al. 2008, 2010; Valko et al. 2009). On each trial of both CPT versions, a bold letter was presented for $150 \mathrm{~ms}$ subtending $0.6^{\circ}$ viewing angle horizontally and $0.8^{\circ}$ vertically at $120 \mathrm{~cm}$ viewing distance against a light grey background in the centre of a 17-inch $(43 \mathrm{~cm})$ cathode ray tube monitor. Since the Flanker-CPT incorporates two additional flanker letters that had to be ignored, horizontal viewing angle was approximately $2.0^{\circ}$ (see Fig. 1). 


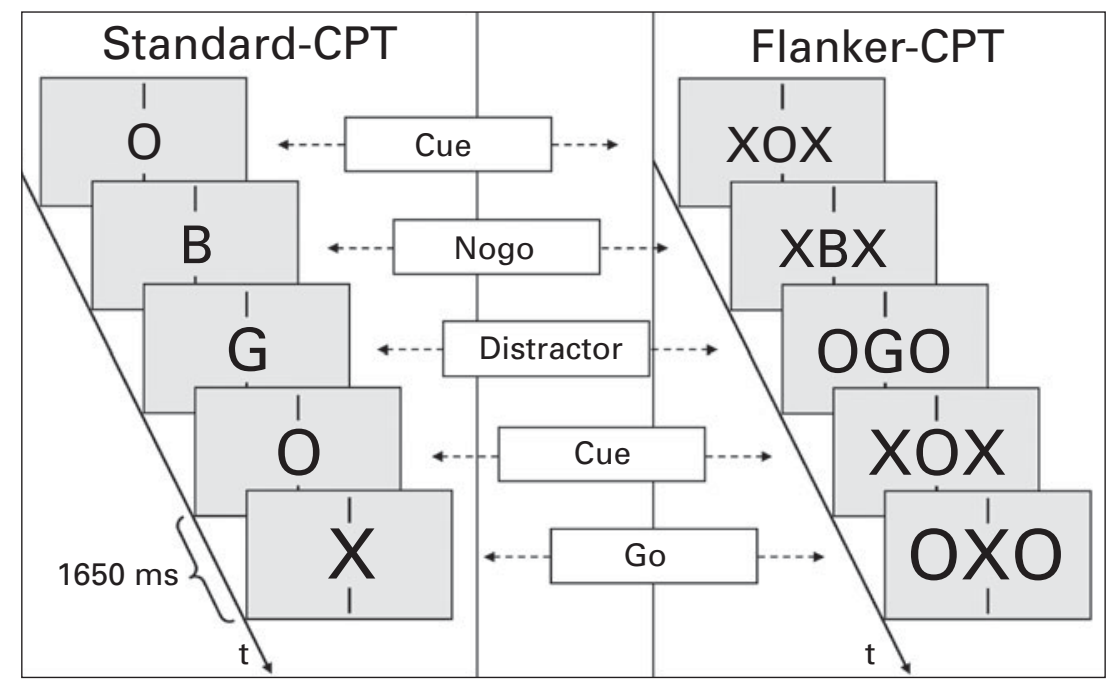

Fig. 1. Task description. Standard Continuous Performance Test (Standard-CPT) and Flanker-CPT in comparison. In both tasks, a sequence of relevant letters was presented in the centre of a screen between two vertical fixation marks. Participants were instructed to respond if a cue A was followed by X, but to withhold responding in all other cases. In the Flanker-CPT, additional distracting letters $\mathrm{X}$ or $\mathrm{O}$ were presented alongside.

In both CPTs, the children had to press the response button with the index finger of their dominant hand only if a central ' $\mathrm{O}$ ' (cues, presented 80 times, see Fig. 1) was followed by a central ' $X$ ' (Go-trials, $n=40$ ), but to withhold responding if the cue was followed by a non-target (NoGo trials, $n=40$ ), or if the ' $X$ ' was uncued (40 trials). Most trials were neutral distractors (letters B, C, D, E, F, G, J or L, $n=20$ each, or the letter $\mathrm{H}, n=80$ ) which also did not require a response, making up a total of 400 trials presented at a rate of $1 / 1650 \mathrm{~ms}$. The sequences and neutral distractors were pseudo-randomly distributed.

The flankers consisted either of O's or X's to induce conflict. Targets and distractors $\mathrm{H}$ were flanked by $\mathrm{O}^{\prime} \mathrm{s}$ ('OXO' and 'OHO'), while cues as well as the remaining distractor stimuli were flanked by $X^{\prime}$ s. As a consequence, cues and cued distractors now required additional response control in terms of inhibition (as they are flanked by target stimuli which can require a response in the context of the CPT paradigm). Cued targets require additional response control in terms of execution (since the flanking cue stimuli would require no response).

Both CPTs lasted $11 \mathrm{~min}$ following 25 practice trials. Their order was counter-balanced after $5 \mathrm{~min}$ of resting EEG with a $13 \mathrm{~min}$ action-monitoring task in between, and short breaks between tasks as desired.

\section{Electrophysiological recording and processing}

For the subjects assessed in Göttingen, the EEG was recorded with $\mathrm{Ag} / \mathrm{AgCl}$ electrodes from 24 sites according to an extended 10-20 system using a BrainAmp amplifier (BrainProducts, Germany) including the $\mathrm{FCz}$ recording reference, a $500 \mathrm{~Hz}$ sampling-rate, $0.016-100 \mathrm{~Hz}$ filters, a $50 \mathrm{~Hz}$ notch filter, and a ground electrode placed on the forehead. The electrooculogram (EOG) was recorded from additional electrodes placed above and below the right eye and at the outer canthi. In Zürich, the EEG was recorded in the same way except for including additional channels, and using a SynAmps amplifier (Neuroscan, USA) and Fpz as reference at $500 \mathrm{~Hz}$ with $0.1-70 \mathrm{~Hz}$ filters. The EOG was recorded from electrodes below the eyes. Impedances were kept below $10 \mathrm{k} \Omega$. Post-processing (see below) eliminated all differences between sites to ensure full compatibility.

Altogether 24 common electrodes were analysed here. After down-sampling to $256 \mathrm{~Hz}$, the EEG was rereferenced to the average reference and filtered offline with $0.1-30 \mathrm{~Hz}, 24 \mathrm{db} /$ oct Butterworth filters. Occular artefacts were corrected using a linear regression method without raw average subtraction (Gratton et al. 1983). If the amplitude at any EEG electrode exceeded $\pm 100 \mu \mathrm{V}$, a section -100 to $+800 \mathrm{~ms}$ around was excluded from further analyses. Segments -125 to $1875 \mathrm{~ms}$ around stimulus onset of Cue, Go and NoGo trials with correct responses [i.e. no responses on cues and NoGo trials, responses ('hits') on Go trials] were subsequently visually checked and averaged. All averages contained at least 15 sweeps. To avoid distortion of ERP topography, no baseline subtraction was applied.

\section{Analyses}

The performance parameters mean reaction time (RT) of correct target responses and inter-individual RT 
variability (RT-SD) were analysed in an analysis of variance (ANOVA) with the between-subject factor Group (controls $v$. non-affected siblings $v$. children with ADHD) and the within-subject factor Task (Standard$\mathrm{CPT} v$. Flanker-CPT). Since commission errors in Go trials and false alarms in NoGo trials were rare and distribution was not normal, accuracy was analysed non-parametrically with Wilcoxon tests on the factor Task for the total sample, and overall Kruskal-Wallis tests on the factor Group followed by post hoc MannWhitney $U$ tests separately for each task.

The CNVs following Cues over centro-parietal electrodes (Fig. 2) were analysed as mean amplitudes from 1200 to $1650 \mathrm{~ms}$ at electrodes $\mathrm{Cz}$ and Pz. The Cue- and Go-P3 had a parietal maximum and were scored as the most positive peak in the time-frame 250 to $700 \mathrm{~ms}$ at electrode Pz (see Figs 2 and 3), while the NoGo-P3 was maximal at fronto-central sites and thus scored 300 to $550 \mathrm{~ms}$ at FCz (Fig. 4). The electrophysiological parameters were analysed using ANOVAs with the between-subject factor 'Group' and within-subject factors 'Task' and 'Site' (centroparietal electrodes $\mathrm{Cz}$ and $\mathrm{Pz}$ for $\mathrm{CNV}$, fronto-central electrodes Fz, FCz and $\mathrm{Cz}$ for NoGo-P3 and electrodes $\mathrm{Cz}, \mathrm{P} 3, \mathrm{Pz}, \mathrm{P} 4$ and $\mathrm{Oz}$ for Cue- and Go-P3 which are maximal over the mid-parietal cortex).

Familiality is indicated by a significant Group main effect or interaction with the factor Group, and by significant differences of the means between controls and ADHD as well as between controls and nonaffected siblings, which was tested in post hoc analyses of confidence intervals with $p<0.05$. The functional significance of the ERP components and their relation to general cognitive ability was explored in the control group through partial correlations between ERP amplitudes, and CPT performance parameters (controlled for age as an indicator of developmental trends in the assessed parameters that may lead to artificial correlations).

The scalp topography of ERP group differences was explored using $t$-maps. ERP sources were calculated using standardized low-resolution electromagnetic tomography (sLORETA) (Fuchs et al. 2002; PascualMarqui, 2002) for each group's average ERP component.

\section{Results}

\section{Performance data}

RTs of correct responses

Correct reactions to cued targets were slower in the Flanker-CPT than in the Standard-CPT (Task: $\left.F_{1,164}=50.9, p<0.01, \eta_{\mathrm{p}}^{2}=0.24\right)$. There was also a trend towards group differences (Group: $F_{2,164}=2.8, p=0.06$, $\eta_{\mathrm{p}}^{2}=0.03$; non-affected siblings, and as a tendency also
ADHD patients responded slower than controls), but no Group $\times$ Task interaction $\left(F_{2,164}=2.2, p=0.11\right.$, $\left.\eta_{\mathrm{p}}^{2}<0.03\right)$. For means and standard deviations and further details of the performance data statistics, see Table S2 of the Supplementary material.

\section{RT-SDs of correct responses}

Intra-individual standard deviations of RTs (RT-SDs) were higher in the Flanker-CPT than in the StandardCPT (Task: $F_{1,164}=5.5, p=0.02, \eta_{\mathrm{p}}^{2}=0.03$ ). ADHD patients had higher RT-SDs than both non-affected siblings and controls (Group: $F_{2,164}=4.4, p=0.01$, $\left.\eta_{\mathrm{p}}^{2}=0.05\right)$.

Hit rate

Since performance accuracy was generally high and close to ceiling, it was analysed non-parametrically. In an overall comparison, the tasks did not differ regarding hit rate (Wilcoxon test, $Z=1.0, p=0.31$ ). Patients with ADHD performed less accurately than controls in both tasks, and less accurately than non-affected siblings for the Standard-CPT only (overall Kruskal-Wallis $\chi_{(2)}^{2}>11.3, p<0.01$ and post-hoc Mann-Whitney $U$ tests $p<0.03$; for all other post-hoc comparisons $p>0.14$ ).

\section{False alarms}

The Flanker-CPT provoked more false alarms than the Standard-CPT (Wilcoxon test, $Z=6.9, p<0.01$ ), but neither task revealed group differences $\left(\chi_{(2)}^{2}<2.2\right.$, $p>0.35)$.

\section{ERP data}

\section{Cue-P3}

The Cue-P3 with its parietal maximum had sources localized by SLORETA in the superior parietal cortex [Brodmann Area (BA) 5, 7, 31 and 40; see Fig. 2]. The latency detected at $\mathrm{Pz}$ was prolonged in the FlankerCPT [marginal means 534 (S.D.=122) ms v. 558 (S.D. $=118)$ ms, Task: $\left.F_{1,164}=8.3, p<0.01, \eta_{\mathrm{p}}^{2}=0.05\right)$, but similar in the three groups (Group: $F_{2,164}=0.2, p>0.50$, $\eta_{\mathrm{p}}^{2}<0.01$, and Task $\times$ Group: $F_{2,164}=1.5, \quad p=0.22$, $\left.\eta_{\mathrm{p}}^{2}=0.02\right)$.

Cue-P3 amplitude was largest at the middle-parietal site $\mathrm{Pz}$ (compared with the surrounding electrodes; Site: $\left.F_{4,656}=101.4, p<0.01, \eta_{\mathrm{p}}^{2}=0.38\right)$, and showed a more anterior topography in the Flanker-CPT (positivity larger at $\mathrm{Cz}$ and diminished at $\mathrm{Oz}$, Task $\times$ Site: $\left.F_{4,656}=8.1, p<0.01, \eta_{\mathrm{p}}^{2}=0.05\right)$. Moreover, the Cue-P3 showed familiality effects (Group: $F_{2,164}=4.0, p=0.02$, $\left.\eta_{\mathrm{p}}^{2}=0.05\right)$, with significantly larger amplitudes in controls than in ADHD, and as a tendency $(p=0.08)$ the intermediate values of the non-affected siblings 
Standard-CPT

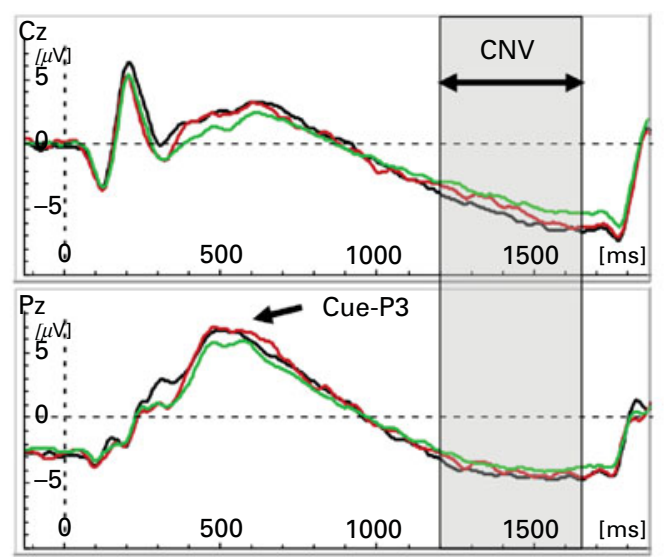

Flanker-CPT

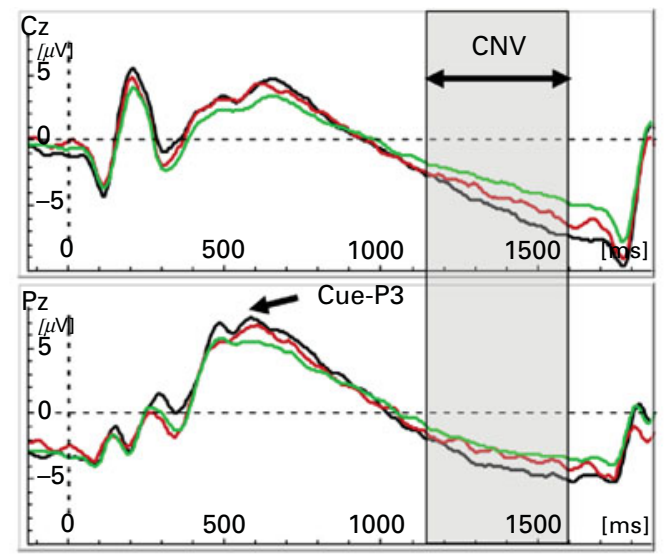

\section{Cue-P3}
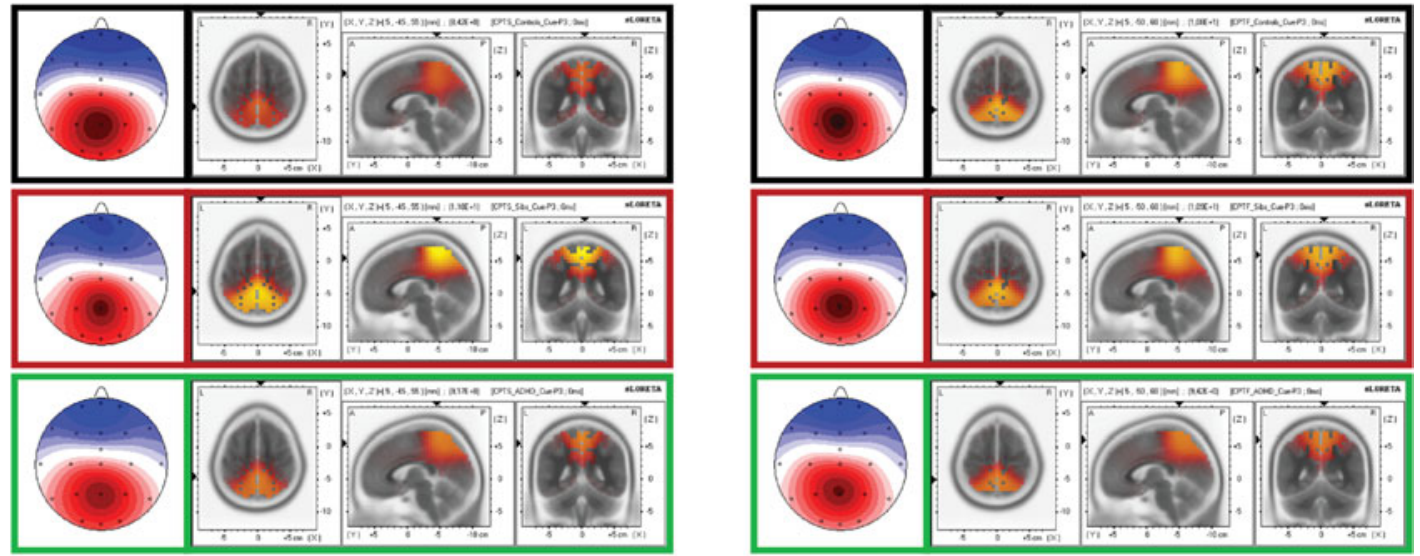

$-10.0 \mu \mathrm{V}$

$0 \mu \mathrm{V}$

$10.0 \mu \mathrm{V}$

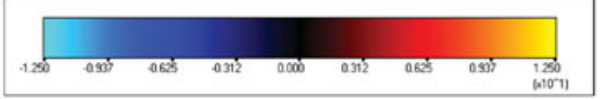

CNV
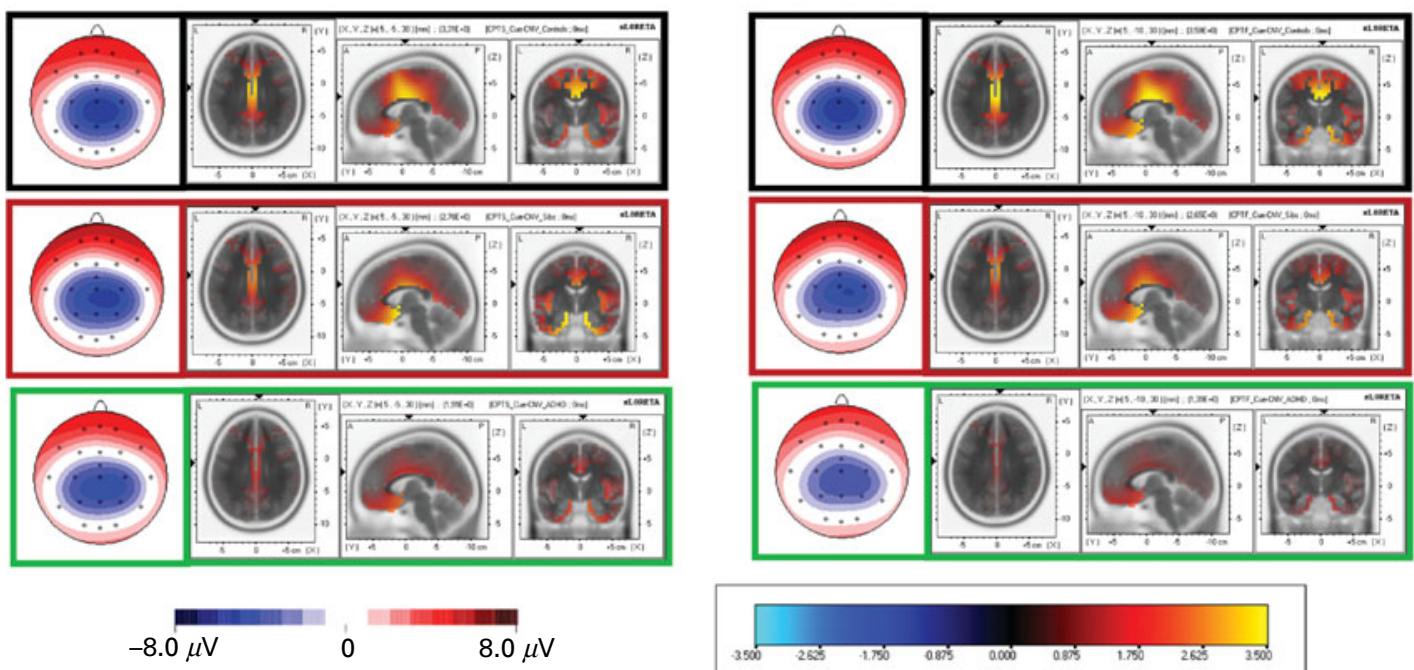

\section{Controls}

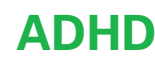

Fig. 2. Topography and sources of the Cue-P3 and the contingent negative variation (CNV). Stimulus-locked grand average waves (above) of controls, non-affected siblings and attention deficit-hyperactivity disorder (ADHD) patients with splineinterpolated maps and standardized low-resolution electromagnetic tomography (sLORETA) source localizations of the Cue-P3 (middle) and mean CNV (below, mean area 1200 to 1650 ms post-cue onset) evoked by correct responded cues. CPT, Standard Continuous Performance Test. 
Standard-CPT
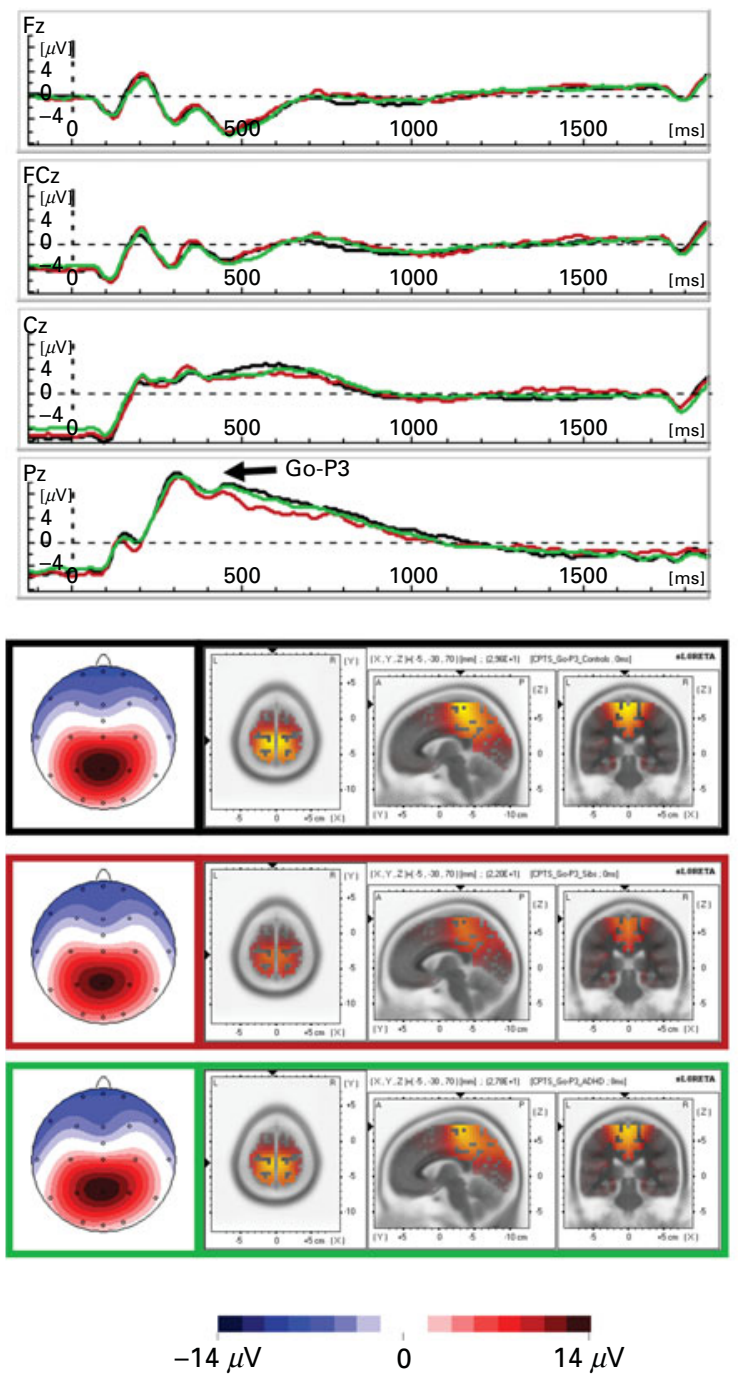

Flanker-CPT
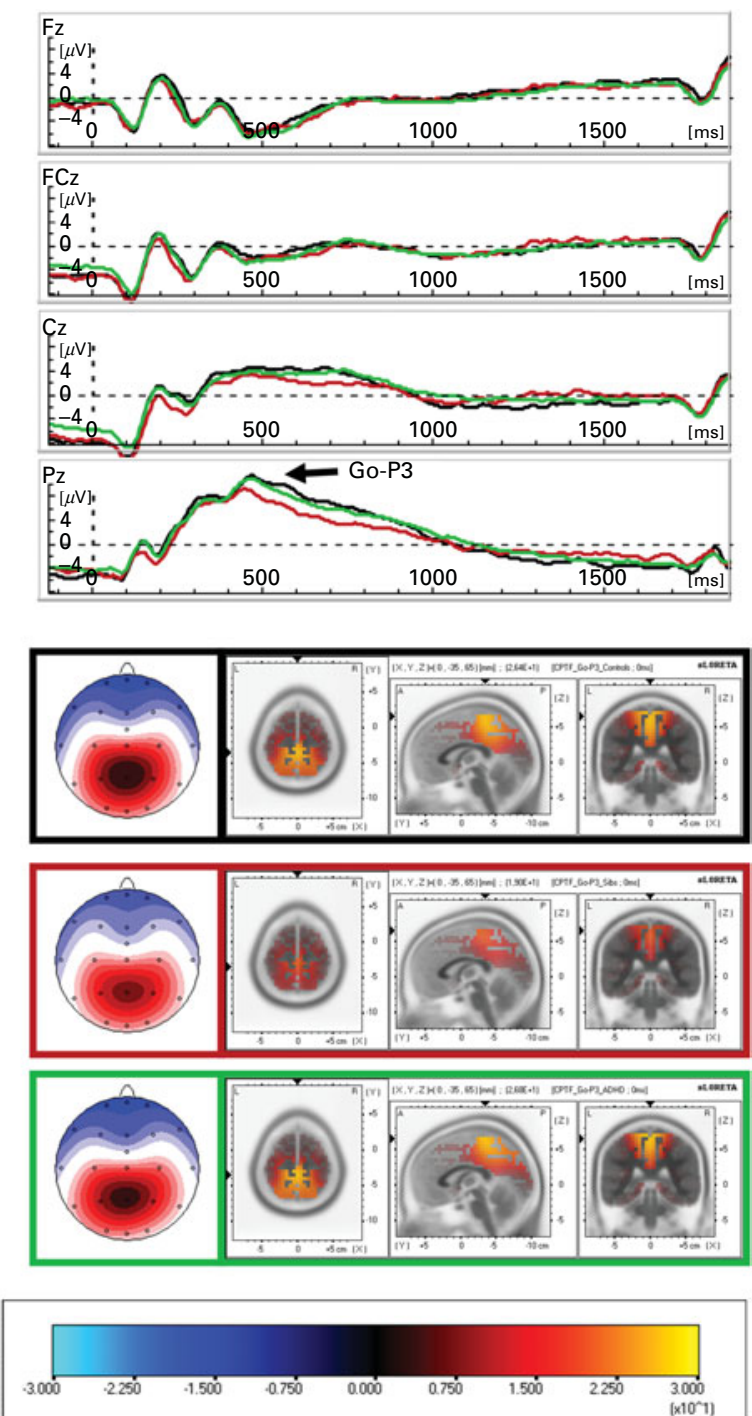

ADHD

\section{Controls}

Fig. 3. Topography and sources of the Go-P3. Stimulus-locked grand average waves of controls, non-affected siblings and attention deficit-hyperactivity disorder (ADHD) patients with spline-interpolated Go-P3 maps evoked by cued targets with correct responses (hits). CPT, Standard Continuous Performance Test.

also differed from both groups. T-maps revealed significantly diminished Cue-P3 amplitude in casecontrol and non-affected siblings-control comparisons at parietal and occipital sites. For further details, see Table S3 and Fig. S1a of the Supplementary material.

\section{Cue-CNV}

The CNV following cues shows the characteristic transient negativity with centro-parietal maximum that terminates with the onset of the following stimulus. Source localizations using sLORETA detected activity in the medial frontal cortex and rostral and dorsolateral cingulate cortex (BA 6, 11 and 24; see Fig. 2). Particularly for the Flanker-CPT, the CNV mean amplitude following cues was largest at $\mathrm{Cz}$ (Site: $F_{1,164}=31.4, p<0.01, \eta_{\mathrm{p}}^{2}=0.16$, and Task $\times$ Site: $\left.F_{1,164}=4.5, p=0.04, \eta_{\mathrm{p}}^{2}=0.03\right)$. It was generally diminished for boys with ADHD as compared with both their non-affected siblings and controls, and nonaffected siblings showed smaller CNVs than controls (Group: $F_{2,164}=9.7, p<0.01, \eta_{\mathrm{p}}^{2}=0.11$ ). Moreover, this pattern was more prominent for the Flanker-CPT (Task $\times$ Group: $F_{2,164}=3.3, p=0.04, \eta_{\mathrm{p}}^{2}=0.04$ ). 


\section{Nogo-P3}

\section{Standard-CPT}
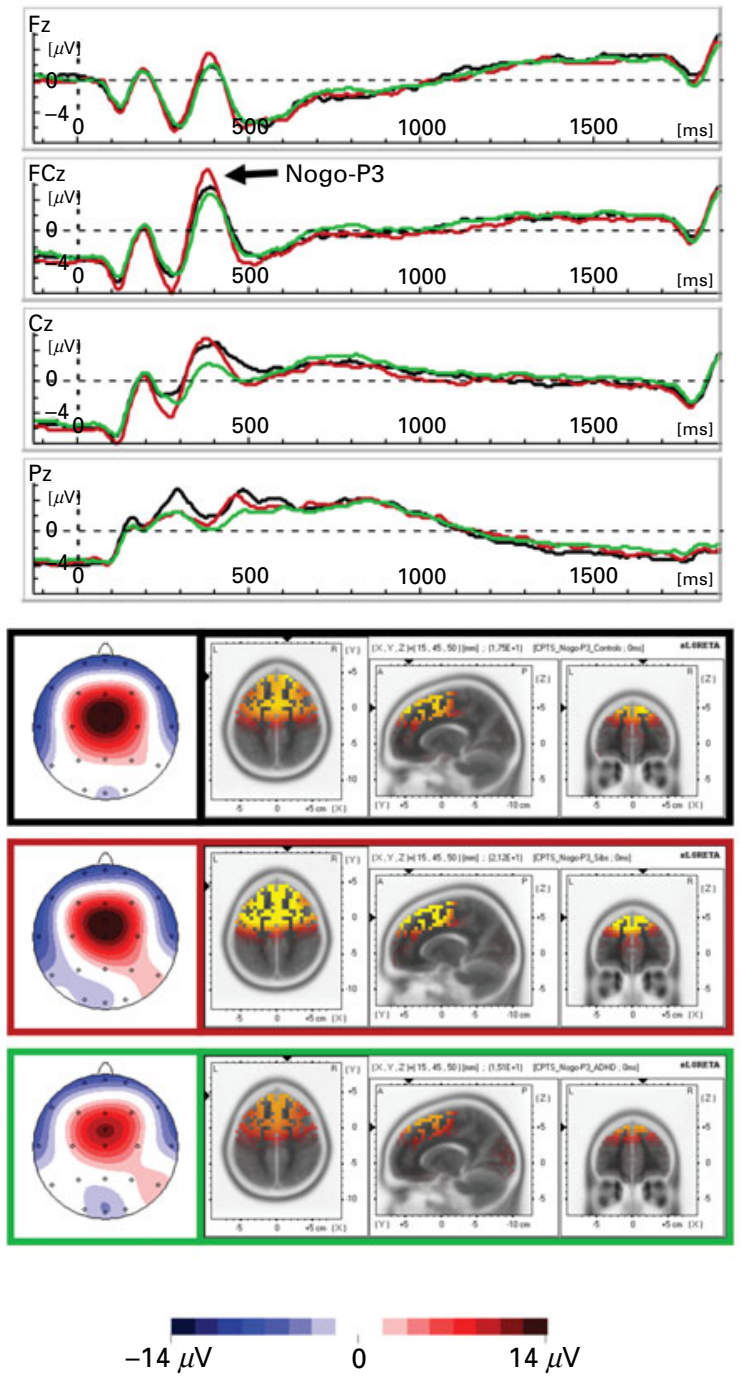

\section{Flanker-CPT}
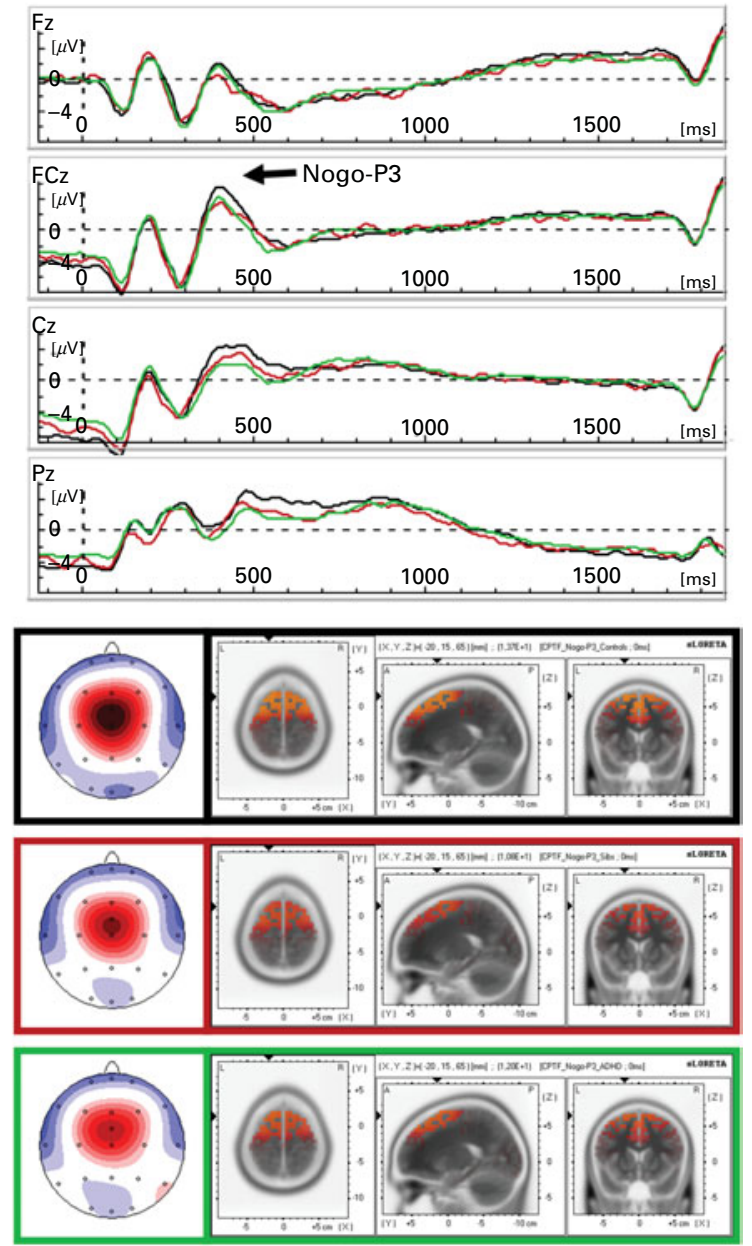

\section{Controls}

Non-affected siblings

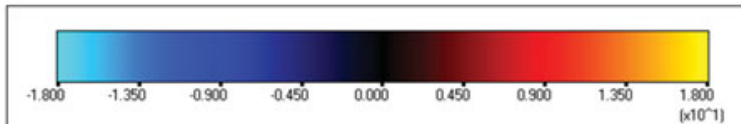

Fig. 4. Topography and sources of the NoGo-P3. Stimulus-locked grand average waves of controls, non-affected siblings and attention deficit-hyperactivity disorder (ADHD) patients with spline-interpolated NoGo-P3 maps evoked by cued non-targets with correctly inhibited responses. CPT, Standard Continuous Performance Test.

The $t$-map comparisons between controls and patients with ADHD or non-affected siblings revealed that the detected effects coincide with the CNV topography. For further details, see Table S3 and Fig. S1b of the Supplementary material.

\section{Go-P3}

The Go-P3 had a parietal maximum with sources detected in the cingulate gyrus, the superior paracentral and parietal lobulae and the praecuneus (BA 5, 7 and
31; see Fig. 4). Its latency was higher for the FlankerCPT [453 (s.D.=107) ms v. 399 (s.D.=120) ms, Task: $\left.F_{1,164}=29.0, p<0.01, \eta_{\mathrm{p}}^{2}=0.15\right]$, and showed no group differences or Task $\times$ Group interactions (both $F_{2,164}$ $\left.<1, p>0.48, \eta_{\mathrm{p}}^{2}<0.01\right)$.

Go-P3 amplitude was highest at Pz (Site: $F_{4,656}=$ 154.0, $p<0.01, \eta_{\mathrm{p}}^{2}=0.48$ ) and showed a tendency towards higher amplitudes in the Standard-CPT at the left-parietal P3 electrode (Task $\times$ Site: $F_{4,656}=2.2$, $\left.p=0.09, \eta_{\mathrm{p}}^{2}=0.02\right)$, without any overall differences between groups or any further significant interactions 

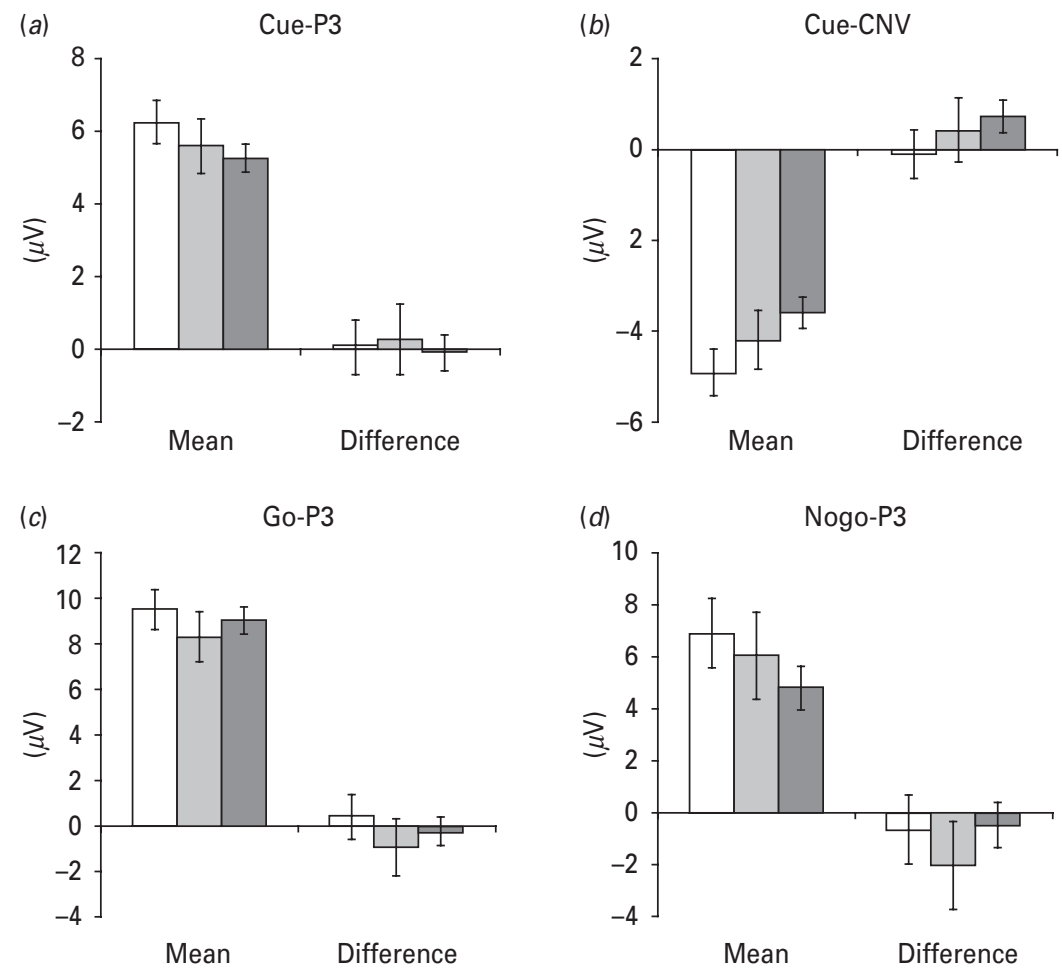

Controls $\square$ Non-affected siblings $\square$ ADHD

Fig. 5. Synopsis of electrophysiological parameters. Means and $95 \%$ confidence intervals with $p<0.05$ for the mean [of Flanker Standard Continuous Performance Test (Flanker-CPT) and Standard-CPT] and difference (Flanker-CPT minus Standard-CPT) event-related potential amplitudes. Impaired cue processing was familially driven in attention deficit-hyperactivity disorder (ADHD), with impairments in (a) Cue-P3 and (b) contingent negative variation (CNV) mean amplitude present in children with ADHD and their non-affected siblings when compared with controls. Patients with ADHD showed (d) further impaired NoGoP3 while non-affected siblings did not differ significantly from either of the other two groups. (c) No clear group differences were evident for the Go-P3.

(all $p>0.21$ ). The $t$-maps showed reduced activity for non-affected siblings at centro-parietal sites (see Table S4 and Fig. S1c of the Supplementary material).

An additional analysis subdividing the Go-P3 into P3a (250-400 ms) and P3b (400-700 ms) components also revealed no familiality effects or interactions.

\section{NoGo-P3}

The NoGo-P3 with its fronto-central maximum showed sLORETA sources in the superior and medial frontal cortex and cingulate gyrus (BA 6, 8, 9, 24 and 32 ; see Fig. 3). Its latency was longer for the FlankerCPT than the Standard-CPT [414 (s.D.=60) ms v. 388 (s.D. $=48) \mathrm{ms}$, respectively, Task: $F_{1,164}=33.7, p<0.01$, $\left.\eta_{\mathrm{p}}^{2}=0.17\right]$ without a main effect of Group or an interaction (both $F_{2,164}<1, p>0.85, \eta_{\mathrm{p}}^{2}<0.01$ ).

The amplitude of the NoGo-P3 was higher in the Standard-CPT (Task: $F_{1,164}=7.8, p<0.01, \eta_{\mathrm{p}}^{2}=0.05$ ), and highest at $\mathrm{FCz}$ (Site: $F_{2,328}=88.5, p<0.01$, $\eta_{\mathrm{p}}^{2}=0.35$ ). It was generally diminished for boys with
ADHD as compared with controls, while non-affected siblings did not differ significantly from either of the other groups (Group: $F_{2,164}=3.8, p=0.03, \eta_{\mathrm{p}}^{2}=0.04$, post hoc controls $>$ ADHD, $p<0.05$, differences involving non-affected siblings both $p>0.20$ ). The $t$-map comparisons showed lower amplitudes for ADHD as compared with controls over central sites for both tasks, and non-affected siblings showed higher amplitudes than ADHD in the Standard-CPT only, but a tendency towards reduction compared with controls in the Flanker-CPT (see Fig. S1d of the Supplementary material).

Fig. 5 summarizes the CNV, Cue-, Go- and NoGo-P3 amplitude findings of the Standard-CPT and FlankerCPT for all groups.

\section{Correlations between performance and ERP parameters}

In the control group, mean RT and RT-SD were positively correlated with mean CNV, while all P3 component amplitudes showed negative correlations (all 
$p<0.05)$. The RT and RT-SD differences between the two CPTs correlated negatively with the respective change in the NoGo-P3 amplitude. General cognitive ability was not related to performance (all $r<0.12$, $p>0.43$ ), and only showed by trend a correlation with mean Go-P3 amplitude (see Fig. S2 of the Supplementary material).

\section{Discussion}

In this study, the time course of familial ADHD effects upon sequential neural markers from preparation to response control was assessed. Behavioural ratings obtained from parents and teachers with the SDQ confirmed the problems in children with ADHD, while strengths and difficulties were within the normal range for healthy siblings and controls. The mean hyperactivity scores of non-affected siblings also fell within the normal range but were slightly higher than for controls. The aim of this study was to assess brain processes during the time course from preparation to response execution or control along with the impact of stimulus incongruency.

\section{Performance}

Means and variability of correct response RT as well as false alarm rate confirm that the Flanker-CPT is generally more demanding than the Standard version. The main RT analyses indicate that robust CPT performance impairments in ADHD are limited to the intra-individual RT variability, which is regarded as a particularly sensitive (van Leeuwen et al. 1998; Banaschewski et al. 2003; Klein et al. 2006), albeit probably not specific, marker of ADHD. Responses to cued targets were slower in the Flanker-CPT than in the Standard-CPT, which probably reflects the additional attentional load imposed by the flanking targets by cue stimuli that (if presented centrally) would not require a response. Post hoc tests provided some evidence that the Flanker-CPT is also capable of uncovering slower responses in patients with ADHD, as also reported for more demanding tasks tapping cognitive control (Albrecht et al. 2008) and for the FlankerCPT in adults with ADHD (McLoughlin et al. 2010, 2011). Accuracy was lower in the ADHD patients than in the other two groups irrespective of task version. Thus, these results indicate that children with ADHD display several problems in CPT performance, consistent with most previous studies (van Leeuwen et al. 1998; Banaschewski et al. 2003). However, as nonaffected siblings did not consistently display intermediate results, overt behavioural CPT performance in ADHD may be less subject to shared familial factors. This is in contrast to our previous findings regarding action monitoring and may reflect specific qualitative differences in task demands (Albrecht et al. 2008, 2009).

\section{ERPs}

Cue processing appears to be the most consistent familially driven electrophysiological deficit in childhood ADHD in this test. Following the presentation of a cue which indicates that the next stimulus may be relevant for task performance, children with ADHD and also to a smaller degree their non-affected siblings showed diminished brain activity related to attentional orienting to the cue as reflected in the Cue-P3 with sources in the parietal lobe. The subsequent preparation for or anticipation of the next trial following cues was also familially driven as reflected by a markedly reduced $\mathrm{CNV}$ in children with ADHD as compared with controls, while non-affected siblings had intermediate activity. CNV was diminished by increasing conflict through additional flankers in nonaffected siblings and in ADHD boys as compared with controls whose $\mathrm{CNV}$ remained stable. This indicates that incompatible stimuli implicating response conflict and accordingly increasing attentional load efficiently hampered preparatory processes in ADHD (Valko et al. 2009; Doehnert et al. 2010; McLoughlin et al. 2010), which is in agreement with previously reported difficulties in action monitoring (Albrecht et al. 2008). Consequently, group differences were particularly pronounced in the more challenging Flanker-CPT, which suggests that impaired processing of conflicting signals shows familiality in ADHD already for preparatory activity, and may thus indicate that shared environmental or genetic factors have an impact on cognitive control even during response preparation. Sources of CNV were located in the dorsal and rostral cingulate cortex, consistent with the hypothesis that $\mathrm{CNV}$ reductions may be a consequence of impaired dopaminergic modulations. Since several studies have shown that the CNV can be increased by successful neurofeedback training (Heinrich et al. 2004; Doehnert et al. 2008; Wangler et al. 2010), these findings demonstrate that even trait-like endophenotype markers can change with effective behavioural treatment, and may reflect the plasticity of dopaminergic functions which can also be altered by working memory training (McNab et al. 2009). Conversely, one may speculate which shared familial factors influence CNV: it may be that potential genetic factors related to the dopaminergic system along with environmental factors within the family like psychosocial interactions, participation in intellectual and physical activities (Nigg et al. 2010; Halperin \& Healey, 2011) or stress may play important roles. 
Both Go- and NoGo-P3s had longer latencies in the Flanker-CPT. Since Go-P3 latency was positively correlated with Go-RT, this probably reflects additional time needed for conflict resolution due to processing of incongruent stimuli (Kok, 2001). The amplitude of the NoGo-P3 was diminished after incongruent stimuli but reflected less clearly familiality of ADHD. It was significantly diminished in boys with ADHD as compared with controls and intermediate in nonaffected siblings, but the siblings' scores did not differ significantly from either of the other two groups. Impairments detected for NoGo-P3 amplitude did not extend towards the Go-P3. Executive response control in Go trials was associated with a large positive deflection maximal at posterior electrodes that peaked (like the NoGo-P3) earlier in the Standard-CPT than in the Flanker-CPT. We found no Go-P3 differences in latency or amplitude between groups, consistent with previous findings using this type of CPT (van Leeuwen et al. 1998; Banaschewski et al. 2003), although such reductions have also been reported in highly co-morbid ADHD samples (Overtoom et al. 1998; Banaschewski et al. 2003).

The functional meaning of these ERP parameters was assessed in the control sample, in order to avoid artificial relationships due to group differences or potential confounds in ADHD symptom severity. In general, CPT performance and the assessed ERP components were not related to differences in cognitive ability in the control group. This supports our approach to conduct analysis which does not control for IQ differences between the groups and suggests that IQ cannot explain the reported findings. Moreover, a diminished IQ as often reported in ADHD research may be a consequence of the symptomatology, which would question the need for a statistical adjustment. Larger (negative) CNV as well as (positive) Go- and NoGo-P3 amplitudes were associated with faster and more homogeneous RTs in both task versions; the additional cognitive control needed in the Flanker-CPT compared with the Standard-CPT led to slower and more variable performance, which was significantly correlated with the respective reduction in NoGo-P3 amplitude. This highlights that brain activity reflected in these ERP parameters may be crucial for proper performance.

These ERP parameters and the underlying constructs also relate to several components of the cognitive energetic model of ADHD (Sergeant, 2005): particularly the diminished Cue-P3 and CNV amplitudes correlate with performance and may index attentional orienting and subsequent activation problems in ADHD and also non-affected siblings. Higher cognitive load due to additional incompatible flankers may affect effort available for processing the target stimuli, and consequently increase familially driven problems in ADHD.

\section{Limitations}

The current study has a number of limitations that need to be considered in the evaluation of the results.

Although the sample size of the current study ( $n$ 167) is relatively large for a clinical ERP investigation, the study may still be limited by statistical power. With $\alpha$ set to $5 \%$, and power to $80 \%$, it is possible to detect a medium effect size $\left(\eta_{\mathrm{p}}^{2}>5.5 \%\right.$ explained variance) between the three groups. This statistical power is sufficient to detect the medium to large differences between ADHD cases and controls commonly reported for performance and several electrophysiological parameters in post hoc pairwise comparisons, but differences between the ADHD cases and the (intermediate) non-affected siblings may be of considerably lower effect size. The sample size required to detect small-to-medium effect sizes would be 260 , and accepting also a trend with $\alpha$ set to $10 \%$ as a control-sibling difference would require at least 204.

As a consequence, this study may have failed to detect possible small sibling-control effects, but our differences between non-affected siblings and controls were even below Cohen's suggestion for small effect sizes $(d=0.12)$ for the mean NoGo-P3 amplitude, and for the Go-P3 where no familiality at all was detected, the differences between the three groups were even smaller. Taken together, our conclusion that particularly cue processing is familially driven in ADHD remains supported despite the limited statistical power of the study. ADHD case-control differences in the CPTs NoGo-P3 related to terminal response control did not show clear familiality: although the nonaffected sibling group mean was intermediate between controls and ADHD children, they did not statistically differ from either one, and the small effect size of the sibling-control differences suggests a very limited practical importance. Other tasks with more demands on response inhibition like Stop-NoGo or Go-NoGo tasks with more Go-Go than NoGo trials may be better capable of showing familiality in these 'inhibitory' parameters. This is further supported by the current data, since the non-affected siblings also showed a strong reduction in NoGo-P3 amplitude with additional incongruent flankers.

A second limitation of the current study is the source localization precision of the assessed ERPs. For a clinical study with children suffering from attention deficits, hyperactivity and impulsivity, it is necessary to limit the preparation and recording time. As a consequence, the spatial sampling of the electrical 
field on the scalp was limited to a relatively low number of electrodes that could be attached with good electrical impedance (ensuring quality and stability) within a reasonable time in a multicentre study. The 24 scalp electrodes available for the current study are sufficient to capture the basic scalp topography of the evoked potentials, but the precision of the brain electrical neuroimaging is limited. There is considerable evidence that sLORETA gives qualitatively valid source localizations in children and adults with lower numbers of electrodes as long as the potential field is adequately covered, although optimal spatial resolution would require more (at least 64 to 100) electrodes (Ryynanen et al. 2006; Michel \& Brandeis, 2009). Therefore, the sLORETA neuroimaging provided here is clearly limited in resolution.

\section{Conclusion}

Neural ADHD markers of covert preparation following cues, and partly markers of response inhibition in NoGo trials were familially driven in ADHD. These familial ADHD markers reflect specific attentional and inhibitory processing stages correlated with performance, and thus appear crucial for the functional understanding of genetic and environmental pathways leading to ADHD. Particularly preparatory processes as reflected by the Cue-P3 and CNV associated with attentional orienting, resource allocation and preparation or anticipation were significantly impaired in non-affected siblings, which indicates that genetic or environmental factors shared in families with ADHD have an impact on these functions. Moreover, as both preparation and response inhibition depend on attentional load, ADHD familiality effects seemed to become larger if the going gets tough.

\section{Supplementary material}

For supplementary material accompanying this paper visit http:/ /dx.doi.org/10.1017/S003329171200270X.

\section{Acknowledgements}

Recruitment of ADHD sibling pairs was supported by National Institute of Mental Health grant no. R01MH062873 to Stephen V. Faraone. D.B. received support from the Swiss National Science Foundation (grant no. 32-109591).

The authors thank all children and their families for participation. Christa Dahlmann, Renate Kolle and Antonia Seitz conducted ERP recordings; Anke Fillmer-Otte, Anne Reiners, Gudrun Schneider and Nicola Wöstmann performed IQ and further neuropsychological testing.

\section{Declaration of Interest}

None.

\section{References}

Albrecht B, Brandeis D, Uebel H, Heinrich H, Heise A, Hasselhorn M, Rothenberger A, Banaschewski T (2009). Action monitoring in children with or without a family history of ADHD - effects of gender on an endophenotype parameter. Neuropsychologia 48, 1171-1178.

Albrecht B, Brandeis D, Uebel H, Heinrich H, Mueller UC, Hasselhorn M, Steinhausen HC, Rothenberger A, Banaschewski T (2008). Action monitoring in boys with attention-deficit/hyperactivity disorder, their nonaffected siblings, and normal control subjects: evidence for an endophenotype. Biological Psychiatry 64, 615-625.

Andreou P, Neale BM, Chen W, Christiansen H, Gabriels I, Heise A, Meidad S, Muller UC, Uebel H, Banaschewski T, Manor I, Oades R, Roeyers H, Rothenberger A, Sham P, Steinhausen HC, Asherson P, Kuntsi J (2007). Reaction time performance in ADHD: improvement under fast-incentive condition and familial effects. Psychological Medicine 37, 1703-1715.

Asherson P, Brookes K, Franke B, Chen W, Gill M, Ebstein RP, Buitelaar J, Banaschewski T, Sonuga-Barke E, Eisenberg J, Manor I, Miranda A, Oades RD, Roeyers H, Rothenberger A, Sergeant J, Steinhausen HC, Faraone SV (2007). Confirmation that a specific haplotype of the dopamine transporter gene is associated with combined-type ADHD. American Journal of Psychiatry 164, 674-677.

Banaschewski T, Brandeis D (2007). Annotation: what electrical brain activity tells us about brain function that other techniques cannot tell us - a child psychiatric perspective. Journal of Child Psychology and Psychiatry and Allied Disciplines 48, 415-435.

Banaschewski T, Brandeis D, Heinrich H, Albrecht B, Brunner E, Rothenberger A (2003). Association of ADHD and conduct disorder - brain electrical evidence for the existence of a distinct subtype. Journal of Child Psychology and Psychiatry and Allied Disciplines 44, 356-376.

Banaschewski T, Brandeis D, Heinrich H, Albrecht B, Brunner E, Rothenberger A (2004). Questioning inhibitory control as the specific deficit of ADHD - evidence from brain electrical activity. Journal of Neural Transmission 111, 841-864.

Banaschewski T, Hollis C, Oosterlaan J, Roeyers H, Rubia K, Willcutt E, Taylor E (2005). Towards an understanding of unique and shared pathways in the psychopathophysiology of ADHD. Developmental Sciences 8, 132-140.

Banaschewski T, Neale BM, Rothenberger A, Roessner V (2007). Comorbidity of tic disorders \& ADHD: conceptual and methodological considerations. European Child and Adolescent Psychiatry 16 (Suppl. 1), 5-14.

Banaschewski T, Yordanova J, Kolev V, Heinrich H, Albrecht B, Rothenberger A (2008). Stimulus context and motor preparation in attention-deficit/hyperactivity disorder. Biological Psychology 77, 53-62. 
Beste C, Saft C, Andrich J, Gold R, Falkenstein M (2008). Response inhibition in Huntington's disease - a study using ERPs and sLORETA. Neuropsychologia 46, 1290-1297.

Brandeis D, van Leeuwen TH, Steger J, Imhof K, Steinhausen H-C (2002). Mapping brain functions of ADHD children. In Recent Advances in Human Brain Mapping (ed. K. Hirata, Y. Koga, K. Nagata and K. Yamazaki), pp. 649-654. Elsevier: Amsterdam.

Buitelaar JK (2005). ADHD: strategies to unravel its genetic architecture. Journal of Neural Transmission. Supplementum 69, 1-17.

Castellanos FX, Tannock R (2002). Neuroscience of attention-deficit/hyperactivity disorder: the search for endophenotypes. Nature Reviews. Neuroscience 3, 617-628.

Conners CK, Sitarenios G, Parker JD, Epstein JN (1998a). The revised Conners' Parent Rating Scale (CPRS-R): factor structure, reliability, and criterion validity. Journal of Abnormal Child Psychology 26, 257-268.

Conners CK, Sitarenios G, Parker JD, Epstein JN (1998b). Revision and restandardization of the Conners Teacher Rating Scale (CTRS-R) : factor structure, reliability, and criterion validity. Journal of Abnormal Child Psychology 26, 279-291.

Dhar M, Been PH, Minderaa RB, Althaus M (2010). Information processing differences and similarities in adults with dyslexia and adults with attention deficit hyperactivity disorder during a continuous performance test: a study of cortical potentials. Neuropsychologia $\mathbf{4 8}$, 3045-3056.

Doehnert M, Brandeis D, Imhof K, Drechsler R, Steinhausen HC (2010). Mapping attention-deficit/ hyperactivity disorder from childhood to adolescence - no neurophysiologic evidence for a developmental lag of attention but some for inhibition. Biological Psychiatry 67, 608-616.

Doehnert M, Brandeis D, Straub M, Steinhausen HC, Drechsler R (2008). Slow cortical potential neurofeedback in attention deficit hyperactivity disorder: is there neurophysiological evidence for specific effects? Journal of Neural Transmission 115, 1445-1456.

Doyle AE, Willcutt EG, Seidman LJ, Biederman J, Chouinard VA, Silva J, Faraone SV (2005).

Attention-deficit/hyperactivity disorder endophenotypes. Biological Psychiatry 57, 1324-1335.

Falkenstein M, Hoormann J, Hohnsbein J (1999). ERP components in Go/NoGo tasks and their relation to inhibition. Acta Psychologica 101, 267-291.

Fallgatter AJ, Bartsch AJ, Herrmann MJ (2002). Electrophysiological measurements of anterior cingulate function. Journal of Neural Transmission 109, 977-988.

Fallgatter AJ, Ehlis AC, Rosler M, Strik WK, Blocher D, Herrmann MJ (2005). Diminished prefrontal brain function in adults with psychopathology in childhood related to attention deficit hyperactivity disorder. Psychiatry Research 138, 157-169.

Fallgatter AJ, Ehlis AC, Seifert J, Strik WK, Scheuerpflug P, Zillessen KE, Herrmann MJ, Warnke A (2004). Altered response control and anterior cingulate function in attention-deficit/hyperactivity disorder boys. Clinical Neurophysiology 115, 973-981.
Fallgatter AJ, Mueller TJ, Strik WK (1999). Age-related changes in the brain electrical correlates of response control. Clinical Neurophysiology 110, 833-838.

Fallgatter AJ, Strik WK (1999). The NoGo-anteriorization as a neurophysiological standard-index for cognitive response control. International Journal of Psychophysiology 32, 233-238.

Fan J, Kolster R, Ghajar J, Suh M, Knight RT, Sarkar R, McCandliss BD (2007). Response anticipation and response conflict: an event-related potential and functional magnetic resonance imaging study. Journal of Neuroscience 27, 2272-2282.

Faraone SV, Perlis RH, Doyle AE, Smoller JW, Goralnick JJ, Holmgren MA, Sklar P (2005). Molecular genetics of attention-deficit/hyperactivity disorder. Biological Psychiatry 57, 1313-1323.

Fuchs M, Kastner J, Wagner M, Hawes S, Ebersole JS (2002). A standardized boundary element method volume conductor model. Clinical Neurophysiology 113, 702-712.

Gomez CM, Marco J, Grau C (2003). Preparatory visuo-motor cortical network of the contingent negative variation estimated by current density. Neuroimage 20, 216-224.

Goodman R (1997). The Strengths and Difficulties Questionnaire: a research note. Journal of Child Psychology and Psychiatry and Allied Disciplines 38, 581-586.

Gratton G, Coles MG, Donchin E (1983). A new method for off-line removal of ocular artifact. Electroencephalography and Clinical Neurophysiology 55, 468-484.

Halperin JM, Healey DM (2011). The influences of environmental enrichment, cognitive enhancement, and physical exercise on brain development: can we alter the developmental trajectory of ADHD? Neuroscience and Biobehavioral Reviews 35, 621-634.

Heinrich H, Gevensleben H, Freisleder FJ, Moll GH, Rothenberger A (2004). Training of slow cortical potentials in attention-deficit/hyperactivity disorder: evidence for positive behavioral and neurophysiological effects. Biological Psychiatry 55, 772-775.

Hennighausen K, Schulte-Korne G, Warnke A, Remschmidt H (2000). Contingent negative variation $(\mathrm{CNV})$ in children with hyperkinetic syndrome - an experimental study using the Continuous Performance Test (CPT) [article in German]. Zeitschrift fur Kinder- und Jugendpsychiatrie und Psychotherapie 28, 239-246.

Himpel S, Banaschewski T, Grüttner A, Becker A, Heise A, Uebel H, Albrecht B, Rothenberger A, Rammsayer T (2009). Duration discrimination in the range of milliseconds and seconds in children with ADHD and their unaffected siblings. Psychological Medicine 39, 1745-1751.

Huang-Pollock CL, Nigg JT, Halperin JM (2006). Single dissociation findings of ADHD deficits in vigilance but not anterior or posterior attention systems. Neuropsychology 20, 420-429.

Kiefer M, Marzinzik F, Weisbrod M, Scherg M, Spitzer M (1998). The time course of brain activations during response inhibition: evidence from event-related potentials in a go/no go task. Neuroreport 9, 765-770. 
Klein C, Wendling K, Huettner P, Ruder H, Peper M (2006). Intra-subject variability in attention-deficit hyperactivity disorder. Biological Psychiatry 60, 1088-1097.

Kok A (2000). Age-related changes in involuntary and voluntary attention as reflected in components of the event-related potential (ERP). Biological Psychology 54, 107-143.

Kok A (2001). On the utility of P3 amplitude as a measure of processing capacity. Psychophysiology 38, 557-577.

Kopp B, Mattler U, Goertz R, Rist F (1996). N2, P3 and the lateralized readiness potential in a NoGo task involving selective response priming. Electroencephalography and Clinical Neurophysiology 99, 19-27.

Kratz O, Studer P, Baack J, Malcherek S, Erbe K, Moll GH, Heinrich H (2012). Differential effects of methylphenidate and atomoxetine on attentional processes in children with ADHD: an event-related potential study using the Attention Network Test. Progress in NeuroPsychopharmacology and Biological Psychiatry 37, 81-89.

Lawrence CA, Barry RJ, Clarke AR, Johnstone SJ, McCarthy R, Selikowitz M, Broyd SJ (2005). Methylphenidate effects in attention deficit/hyperactivity disorder: electrodermal and ERP measures during a continuous performance task. Psychopharmacology 183, 81-91.

Linssen AM, Vuurman EF, Sambeth A, Nave S, Spooren W, Vargas G, Santarelli L, Riedel WJ (2011). Contingent negative variation as a dopaminergic biomarker: evidence from dose-related effects of methylphenidate. Psychopharmacology 218, 533-542.

Loo SK, Hale ST, Hanada G, Macion J, Shrestha A, McGough JJ, McCracken JT, Nelson S, Smalley SL (2010). Familial clustering and DRD4 effects on electroencephalogram measures in multiplex families with attention deficit/hyperactivity disorder. Journal of the American Academy of Child and Adolescent Psychiatry 49, 368-377.

Losier BJ, McGrath PJ, Klein RM (1996). Error patterns on the continuous performance test in non-medicated and medicated samples of children with and without ADHD: a meta-analytic review. Journal of Child Psychology and Psychiatry and Allied Disciplines 37, 971-987.

Lutcke H, Gevensleben H, Albrecht B, Frahm J (2008). Brain networks involved in early versus late response anticipation and their relation to conflict processing. Journal of Cognitive Neuroscience 21, 2172-2184.

McLoughlin G, Albrecht B, Banaschewski T, Rothenberger A, Brandeis D, Asherson P, Kuntsi J (2010). Electrophysiological evidence for abnormal preparatory states and inhibitory processing in adult ADHD. Behavioral and Brain Functions 6, 66.

McLoughlin G, Asherson P, Albrecht B, Banaschewski T, Rothenberger A, Brandeis D, Kuntsi J (2011). Cognitiveelectrophysiological indices of attentional and inhibitory processing in adults with ADHD: familial effects. Behavioral and Brain Functions 7, 26.

McNab F, Varrone A, Farde L, Jucaite A, Bystritsky P, Forssberg H, Klingberg T (2009). Changes in cortical dopamine D1 receptor binding associated with cognitive training. Science 323, 800-802.

Meyer-Lindenberg A, Weinberger DR (2006). Intermediate phenotypes and genetic mechanisms of psychiatric disorders. Nature Reviews. Neuroscience 7, 818-827.

Michel CM, Brandeis D (2009). Data acquisition standards for electrical neuroimaging. In Electrical Neuroimaging (ed. C. M. Michel, T. Koenig, D. Brandeis, L. R. R. Gianotti and J. Wackermann), pp. 1-24. Cambridge University Press: Cambridge.

Nigg J, Nikolas M, Burt SA (2010). Measured gene-byenvironment interaction in relation to attention-deficit/ hyperactivity disorder. Journal of the American Academy of Child and Adolescent Psychiatry 49, 863-873.

Overtoom CC, Verbaten MN, Kemner C, Kenemans JL, van Engeland H, Buitelaar JK, Camfferman G, Koelega HS (1998). Associations between event-related potentials and measures of attention and inhibition in the Continuous Performance Task in children with ADHD and normal controls. Journal of the American Academy of Child and Adolescent Psychiatry 37, 977-985.

Pascual-Marqui RD (2002). Standardized low-resolution brain electromagnetic tomography (sLORETA): technical details. Methods and Findings in Experimental and Clinical Pharmacology 24 (Suppl. D), 5-12.

Pennington BF, Ozonoff S (1996). Executive functions and developmental psychopathology. Journal of Child Psychology and Psychiatry and Allied Disciplines 37, 51-87.

Perchet C, Revol O, Fourneret P, Mauguiere F, Garcia-Larrea L (2001). Attention shifts and anticipatory mechanisms in hyperactive children: an ERP study using the Posner paradigm. Biological Psychiatry 50, 44-57.

Pfefferbaum A, Ford JM, Weller BJ, Kopell BS (1985). ERPs to response production and inhibition. Electroencephalography and Clinical Neurophysiology 60, 423-434.

Plummer C, Humphrey N (2008). Time perception in children with ADHD: the effects of task modality and duration. Child Neuropsychology 15, 147-162.

Polich J, Kok A (1995). Cognitive and biological determinants of P300: an integrative review. Biological Psychology 41, 103-146.

Rommelse NN, Altink ME, Oosterlaan J, Buschgens CJ, Buitelaar J, De Sonneville LM, Sergeant JA (2007a). Motor control in children with ADHD and non-affected siblings: deficits most pronounced using the left hand. Journal of Child Psychology and Psychiatry and Allied Disciplines 48, 1071-1079.

Rommelse NN, Oosterlaan J, Buitelaar J, Faraone SV, Sergeant JA (2007b). Time reproduction in children with ADHD and their nonaffected siblings. Journal of the American Academy of Child and Adolescent Psychiatry 46, 582-590.

Rosvold HE, Bransome Jr ED, Mirsky AF, Rosvold HE, Sarason I (1956). A continuous performance test of brain damage. Journal of Consulting Psychology 20, 343-350.

Rubia K, Overmeyer S, Taylor E, Brammer M, Williams SC, Simmons A, Bullmore ET (1999). Hypofrontality in attention deficit hyperactivity disorder during higherorder motor control: a study with functional MRI. American Journal of Psychiatry 156, 891-896. 
Ryynanen OR, Hyttinen JA, Malmivuo JA (2006). Effect of measurement noise and electrode density on the spatial resolution of cortical potential distribution with different resistivity values for the skull. IEEE Transactions on Biomedical Engineering 53, 1851-1858.

Sattler JM (1992). Assessment of Children: Wisc-III and Wppsi-R Supplement. Jerome M. Sattler: San Diego.

Sergeant JA (2005). Modeling attention-deficit/hyperactivity disorder: a critical appraisal of the cognitive-energetic model. Biological Psychiatry 57, 1248-1255.

Slaats-Willemse D, Swaab-Barneveld H, de Sonneville L, van der Meulen E, Buitelaar J (2003). Deficient response inhibition as a cognitive endophenotype of ADHD. Journal of the American Academy of Child and Adolescent Psychiatry 42, 1242-1248.

Smith AB, Taylor E, Brammer M, Halari R, Rubia K (2008). Reduced activation in right lateral prefrontal cortex and anterior cingulate gyrus in medication-naive adolescents with attention deficit hyperactivity disorder during time discrimination. Journal of Child Psychology and Psychiatry and Allied Disciplines 49, 977-985.

Strandburg RJ, Marsh JT, Brown WS, Asarnow RF, Higa J, Harper R, Guthrie D (1996). Continuous-processing related event-related potentials in children with attention deficit hyperactivity disorder. Biological Psychiatry 40, 964-980.

Strik WK, Fallgatter AJ, Brandeis D, Pascual-Marqui RD (1998). Three-dimensional tomography of event-related potentials during response inhibition: evidence for phasic frontal lobe activation. Electroencephalography and Clinical Neurophysiology 108, 406-413.

Taylor E, Everitt B, Thorley G, Schachar R, Rutter M, Wieselberg M (1986). Conduct disorder and hyperactivity: II. A cluster analytic approach to the identification of a behavioural syndrome. British Journal of Psychiatry 149, 768-777.

Taylor E, Schachar R, Thorley G, Wieselberg HM, Everitt B, Rutter M (1987). Which boys respond to stimulant medication? A controlled trial of methylphenidate in boys with disruptive behaviour. Psychological Medicine 17, 121-143.

Valko L, Doehnert M, Müller UC, Schneider G, Albrecht B, Drechsler R, Maechler M, Steinhausen HC, Brandeis D (2009). Differences in neurophysiological markers of inhibitory and temporal processing deficits in children and adults with ADHD. Journal of Psychophysiology 23, 235-246.

van Leeuwen TH, Steinhausen HC, Overtoom CC, Pascual-Marqui RD, van't Klooster B, Rothenberger A, Sergeant JA, Brandeis D (1998). The continuous performance test revisited with neuroelectric mapping: impaired orienting in children with attention deficits. Behavioural Brain Research 94, 97-110.

Verleger R, Paehge T, Kolev V, Yordanova J, Jaśkowski P (2006). On the relation of movement-related potentials to the go/no-go effect on P3. Biological Psychology 73, 298-313.

Walter WG, Cooper R, Aldridge VJ, McCallum WC, Winter AL (1964). Contingent negative variation: an electric sign of sensorimotor association and expectancy in the human brain. Nature 203, 380-384.

Wangler S, Gevensleben H, Albrecht B, Studer P, Rothenberger A, Moll GH, Heinrich H (2010). Neurofeedback in children with ADHD: specific event-related potential findings of a randomized controlled trial. Clinical Neurophysiology 122, 942-950.

Weisbrod M, Kiefer M, Marzinzik F, Spitzer M (2000). Executive control is disturbed in schizophrenia: evidence from event-related potentials in a Go/NoGo task. Biological Psychiatry 47, 51-60.

Woerner W, Becker A, Rothenberger A (2004). Normative data and scale properties of the German parent SDQ. European Child and Adolescent Psychiatry 13 (Suppl. 2), II3-II10. 